\title{
Rechallenge with Previously Administered Epidermal Growth Factor Receptor-Tyrosine Kinase Inhibitors in EGFR-Mutated Non-Small Cell Lung Cancer with Leptomeningeal Metastasis
}

\section{Taichi Miyawaki}

Shizuoka Cancer Center: Shizuoka Kenritsu Shizuoka Gan Center Hirotsugu Kenmotsu ( $\sim$ h.kenmotsu@scchr.jp)

Shizuoka Cancer Center https://orcid.org/0000-0003-0590-9259 Michitoshi Yabe

Shizuoka Cancer Center: Shizuoka Kenritsu Shizuoka Gan Center Hiroaki Kodama

Shizuoka Cancer Center: Shizuoka Kenritsu Shizuoka Gan Center Naoya Nishioka

Shizuoka Cancer Center: Shizuoka Kenritsu Shizuoka Gan Center Eriko Miyawaki

Shizuoka Cancer Center: Shizuoka Kenritsu Shizuoka Gan Center Nobuaki Mamesaya

Shizuoka Cancer Center: Shizuoka Kenritsu Shizuoka Gan Center

Haruki Kobayashi

Shizuoka Cancer Center: Shizuoka Kenritsu Shizuoka Gan Center

\section{Shota Omori}

Shizuoka Cancer Center: Shizuoka Kenritsu Shizuoka Gan Center

\section{Kazushige Wakuda}

Shizuoka Cancer Center: Shizuoka Kenritsu Shizuoka Gan Center

\section{Akira Ono}

Shizuoka Cancer Center: Shizuoka Kenritsu Shizuoka Gan Center

Shoichi Deguchi

Shizuoka Cancer Center: Shizuoka Kenritsu Shizuoka Gan Center Koichi Mitsuya

Shizuoka Cancer Center: Shizuoka Kenritsu Shizuoka Gan Center

\section{Tateaki Naito}

Shizuoka Cancer Center: Shizuoka Kenritsu Shizuoka Gan Center Haruyasu Murakami

Shizuoka Cancer Center: Shizuoka Kenritsu Shizuoka Gan Center 


\section{Keita Mori}

Shizuoka Cancer Center: Shizuoka Kenritsu Shizuoka Gan Center

\section{Hideyuki Harada}

Shizuoka Cancer Center: Shizuoka Kenritsu Shizuoka Gan Center

\section{Nakamasa Hayashi}

Shizuoka Cancer Center: Shizuoka Kenritsu Shizuoka Gan Center

\section{Kazuhisa Takahashi}

Juntendo University School of Medicine Graduate School of Medicine: Juntendo Daigaku Igakubu

Daigakuin Igaku Kenkyuka

Toshiaki Takahashi

Shizuoka Cancer Center: Shizuoka Kenritsu Shizuoka Gan Center

\section{Research Article}

Keywords: Non-small cell lung cancer, EGFR mutation, Leptomeningeal metastasis, EGFR-TKI, Rechallenge EGFR-TKI

Posted Date: May 5th, 2021

DOI: https://doi.org/10.21203/rs.3.rs-443274/v1

License: (c) (i) This work is licensed under a Creative Commons Attribution 4.0 International License. Read Full License

Version of Record: A version of this preprint was published at Investigational New Drugs on July 14th, 2021. See the published version at https://doi.org/10.1007/s10637-021-01140-3. 


\section{Abstract}

Objectives: In EGFR-mutated non-small cell lung cancer (NSCLC) patients, approximately $80-90 \%$ of leptomeningeal metastasis (LM) develops after failed initial epidermal growth factor receptor (EGFR) tyrosine kinase inhibitor (EGFR-TKI) treatment. However, the efficacy of rechallenging previously administered EGFR-TKIs in patients with EGFR-mutated NSCLC and LM that develops after EGFR-TKI treatment failure remains unknown.

Materials and Methods: We retrospectively reviewed the medical records of patients with EGFR-mutated NSCLC and LM from November 2011 to August 2019. Patients were classified into two groups according to LM treatment type: switched to previously unadministered EGFR-TKIs (Switch-TKI) and rechallenge with previously administered EGFR-TKIs (Rechallenge-TKI).

Results: In total, 50 patients treated with EGFR-TKI after LM diagnosis were included; 35 were treated with Switch-TKI, and 15 with Rechallenge-TKI. The median overall survival (OS) from the time of LM diagnosis was 6.2 months in all study patients. According to the treatment type, the median OS from the time of LM diagnosis was 6.9 months in Switch-TKI patients and 4.9 months in Rechallenge-TKI patients. There was no significant difference in the OS between the Switch-TKI and Rechallenge-TKI groups $(P=0.864)$. Thirty-five patients were treated with erlotinib and 15 with osimertinib; Regardless of the type for EGFRTKI, there was no significant difference in OS between patients treated with Switch-TKI and those treated with Rechallenge-TKI.

Conclusion: Our findings suggest that rechallenge of previously administered EGFR-TKIs may be a therapeutic option for LM development after EGFR-TKI treatment failure in patients with EGFR-mutated NSCLC, not only switching to previously unadministered EGFR-TKIs.

\section{Introduction}

Leptomeningeal metastasis (LM) develops in 3-5\% of patients with metastatic non-small cell lung cancer (NSCLC) [1-3], and approximately $10 \%$ of patients with epidermal growth factor receptor (EGFR)mutated NSCLC [4-6]. Patients with LM experience rapid deterioration in their neurological function and performance status [1].

Several previous studies have demonstrated that patients with EGFR mutated NSCLC treated with EGFR tyrosine kinase inhibitors (TKIs) have a median survival of approximately 6 to 12 months after diagnosis of LM [1, 4, 7-12]. The concentration and penetration into the cerebrospinal fluid (CSF) of erlotinib were higher than that of gefitinib $[1,7,12,13]$. Indeed, a previous study showed that erlotinib had a better cytologic conversion rate in the CSF than gefitinib in patients with EGFR-mutated NSCLC and LM $[7,13]$. Furthermore, a recent retrospective study showed that osimertinib improves survival regardless of the T790M mutation in patients with EGFR mutated NSCLC and LM [9]. A single-arm prospective study demonstrated that the efficacy of osimertinib was superior to historical data of first- and secondgeneration EGFR-TKIs in patients with EGFR-mutated NSCLC and LM [8]. 
Previous studies have revealed that $80-90 \%$ of LM develops after EGFR-TKI treatment failure $[4,6,9,14]$. The dominant EGFR-TKI treatment sequence for patients with LM development after EGFR-TKI treatment failure has traditionally involved a switch to erlotinib or osimertinib $[4,8,9,11]$. Thus, no study has evaluated the efficacy of rechallenge with previously administered EGFR-TKIs in patients with LM development after EGFR-TKI treatment failure.

A recent phase III study showed that osimertinib was associated with prolonged overall survival (OS) compared to first-generation EGFR-TKIs, including erlotinib and gefitinib [15]. Meanwhile, it is considered to be inevitable that LM may eventually develop after failure of treatment with osimertinib. I For EGFRTKIs with favourable CNS penetration, such as osimertinib or erlotinib, rechallenge with a previously administered EGFR-TKI after the onset of LM may be an effective treatment strategy, not just switching to unadministered EGFR-TKIs. Thus, our retrospective study evaluated the efficacy of both rechallenge with previously administered EGFR-TKIs and switching to unadministered EGFR-TKIs in patients with EGFRmutated NSCLC and LM development after EGFR-TKI treatment failure.

\section{Materials And Methods}

\subsection{Patients and data collection}

We collected and retrospectively reviewed medical records of patients with EGFR-mutated NSCLC and LM at Shizuoka Cancer Center (Shizuoka, Japan) from November 2011 to August 2019. LM was diagnosed based on cytological evidence of malignant CSF or magnetic resonance imaging findings with symptoms. Patients diagnosed with LM before the administration of EGFR-TKIs were excluded from this study.

The following patient details were collected for the analysis: age, sex, Eastern Cooperative Oncology Group performance status (ECOG-PS) at diagnosis of LM, history of smoking, disease stage at diagnosis of lung cancer, number of extra central nervous system (CNS) metastatic sites, EGFR mutation status, type of EGFR-TKI, progressive disease in extra-CNS sites at the onset of LM and time to LM development following metastatic NSCLC diagnosis. We used the commercially available method in Japan to evaluate EGFR mutations using polymerase chain reaction amplification.

\subsection{EGFR-TKI administration for LM and other treatment}

Based on the type of treatment for LM, we classified the patients into two groups: (1) Switch-TKI: switch to previously unadministered EGFR-TKIs and (2) Rechallenge-TKI: rechallenge previously administered EGFR-TKIs. Additionally, we evaluated other treatments for LM aside from systemic therapy, including whole brain radiotherapy (WBRT) and palliative CSF shunting [16].

\subsection{Statistical analysis}

We defined overall survival (OS) as the time from LM diagnosis to death, estimated by the Kaplan-Meier method and compared using the log-rank test. We defined time-to-treatment failure (TTF) as the time from EGFR-TKI treatment of LM to treatment discontinuation or death estimated by the Kaplan-Meier 
method and compared using the log-rank test. Potential risk factors were assessed using univariate and multivariate analyses with a Cox proportional hazards model for OS. Covariates in the univariate analyses included age, sex, smoking status, ECOG-PS, initial stage (I-III vs IV), number of extra CNS metastatic sites (1 vs $\geq 2$ ), No PD in extra-CNS sites at the onset of $L M$, osimertinib administration after LM development, WBRT, and EGFR-TKI sequence type (Switch-TKI vs. Rechallenge-TKI). Significant factors from the univariate analyses $(P<0.1)$ and EGFR-TKI sequence type were included in multivariate analyses. The data cutoff date was August 30, 2020. For all analyses, significance was defined as $P<$ 0.05. We performed all analyses using the STATA software (version 14.0; Stata Corp., College Station, TX, USA). Our institutional ethics review board approved the study protocol (approval no. J2020-177-2020-1).

\section{Results}

\subsection{Patient characteristics}

Of the 691 consecutive patients who had EGFR-mutated metastatic NSCLC and were treated with EGFRTKIs, 107 were diagnosed with LM. LM developed after the failure of first-line EGFR-TKI treatment in 90 patients. We excluded 17 patients with LM at the time of metastatic NSCLC diagnosis and 40 patients treated without EGFR-TKIs after LM development. Fifty patients who were diagnosed with LM after EGFRTKI treatment failure and received subsequent treatment with EGFR-TKIs were ultimately included in this study (Fig. 1).

The clinical characteristics of the entire cohort are summarized in Table 1. The majority of the patients were characterized as follows: female (76\%), initial stage IV (84\%), adenocarcinoma (98\%), sensitizing EGFR mutation (98\%), no extra-CNS disease progression (78\%), and neurological symptoms related to LM (88\%). Twelve patients (24\%) had ECOG-PS of 2, and 20 patients (40\%) had ECOG-PS of 3-4 at LM diagnosis. 
Table 1

Characteristics of the Patients at diagnosis of LM

\begin{tabular}{|c|c|c|c|c|}
\hline $\begin{array}{l}\text { Characteristics } \\
N(\%)\end{array}$ & $\begin{array}{l}\text { Total } \\
(n=50) \\
(\%)\end{array}$ & $\begin{array}{l}\text { Switch- } \\
\text { TKI } \\
\left(\begin{array}{l}n=35) \\
(\%)\end{array}\right.\end{array}$ & $\begin{array}{l}\text { Rechallenge- } \\
\text { TKI } \\
(n=15)(\%)\end{array}$ & $\begin{array}{l}P \text { - } \\
\text { value }\end{array}$ \\
\hline Age, median, (range) & $\begin{array}{l}65(37- \\
89)\end{array}$ & $\begin{array}{l}63(37- \\
83)\end{array}$ & $65(43-74)$ & 0.711 \\
\hline Male & $12(24)$ & $8(23)$ & $4(26)$ & 0.773 \\
\hline Female & $38(76)$ & $27(77)$ & $11(74)$ & \\
\hline \multicolumn{5}{|l|}{ ECOG-PS } \\
\hline 0 & $3(6)$ & $3(9)$ & 0 & \multirow[t]{5}{*}{0.753} \\
\hline 1 & $15(30)$ & $11(31)$ & $4(27)$ & \\
\hline 2 & $12(24)$ & $8(23)$ & $4(27)$ & \\
\hline 3 & $18(36)$ & $12(34)$ & $6(40)$ & \\
\hline 4 & $2(4)$ & $1(3)$ & $1(6)$ & \\
\hline Symptoms related to LM & $44(88)$ & $30(86)$ & $14(93)$ & 0.447 \\
\hline \multicolumn{5}{|l|}{ Smoking status } \\
\hline Ever & $18(36)$ & $14(40)$ & $4(27)$ & \multirow[t]{2}{*}{0.368} \\
\hline Never & $32(64)$ & $21(60)$ & $11(73)$ & \\
\hline \multicolumn{5}{|l|}{ Histology } \\
\hline Adenocarcinoma & $49(98)$ & $\begin{array}{l}35 \\
(100)\end{array}$ & $14(93)$ & \multirow[t]{2}{*}{0.123} \\
\hline NSCLC & $1(2)$ & 0 & $1(7)$ & \\
\hline \multicolumn{5}{|l|}{ Stage at initial diagnosis } \\
\hline$|-|||$ & $8(16)$ & $6(17)$ & $2(13)$ & \multirow[t]{2}{*}{0.736} \\
\hline IV & $42(84)$ & $29(83)$ & $13(87)$ & \\
\hline \multicolumn{5}{|l|}{ Initial EGFR mutation } \\
\hline Del 19 & $25(50)$ & $18(51)$ & $7(47)$ & 0.345 \\
\hline
\end{tabular}

LM, leptomeningeal metastases; ECOG, Eastern Cooperative Oncology Group; PS, performance status; NSCLC, non-small cell lung cancer; EGFR, epidermal growth factor receptor; TKI, tyrosine kinase inhibitor; DEL 19, exon 19 deletions; L858R, L858R point mutations; mo, months; CNS, central nervous system. 


\begin{tabular}{|c|c|c|c|c|}
\hline $\begin{array}{l}\text { Characteristics } \\
\mathrm{N}(\%)\end{array}$ & $\begin{array}{l}\text { Total } \\
\left(\begin{array}{l}n=50) \\
(\%)\end{array}\right.\end{array}$ & $\begin{array}{l}\text { Switch- } \\
\text { TKI } \\
\left(\begin{array}{l}n=35) \\
(\%)\end{array}\right.\end{array}$ & $\begin{array}{l}\text { Rechallenge- } \\
\text { TKI } \\
(n=15)(\%)\end{array}$ & $\begin{array}{l}P \\
\text { value }\end{array}$ \\
\hline L858R & $24(48)$ & $16(46)$ & $8(53)$ & \\
\hline Other & $2(1)$ & $1(3)$ & 0 & \\
\hline Secondary EGFR mutation T790M positive & $20(40)$ & $9(25)$ & $11(73)$ & 0.059 \\
\hline \multicolumn{5}{|l|}{ LM diagnosis } \\
\hline Cytology tests & $26(52)$ & $20(57)$ & $6(40)$ & \multirow[t]{2}{*}{0.459} \\
\hline Imaging and symptoms & $24(48)$ & $15(43)$ & $9(60)$ & \\
\hline $\begin{array}{l}\text { Number of extra CNS metastatic sites median, } \\
\text { (range) }\end{array}$ & $3(0-5)$ & $3(0-5)$ & $4(1-5)$ & 0.515 \\
\hline PD in extra CNS sites at the onset of LM & $11(22)$ & $7(20)$ & $4(27)$ & 0.929 \\
\hline $\begin{array}{l}\text { Time to development of LM from the diagnosis of } \\
\text { metastatic NSCLC, mo, median, (range) }\end{array}$ & $\begin{array}{l}18.3 \\
(0.5- \\
71.6)\end{array}$ & $\begin{array}{l}9.2 \\
(0.5- \\
71.6)\end{array}$ & $\begin{array}{l}24.6(8.6- \\
63.5)\end{array}$ & 0.078 \\
\hline \multicolumn{5}{|c|}{$\begin{array}{l}\text { LM, leptomeningeal metastases; ECOG, Eastern Cooperative Oncology Group; PS, performance status; } \\
\text { NSCLC, non-small cell lung cancer; EGFR, epidermal growth factor receptor; TKI, tyrosine kinase } \\
\text { inhibitor; DEL 19, exon } 19 \text { deletions; L858R, L858R point mutations; mo, months; CNS, central nervous } \\
\text { system. }\end{array}$} \\
\hline
\end{tabular}

The treatments after LM development are shown in Supplementary Table 1. All patients were treated with osimertinib or erlotinib. Seven patients were treated with osimertininb in the Rechallenge-TKI group, and nine patients were treated with osimertininb in the Switch-TKI group. Twenty-six patients were treated with erlotinib in the Rechallenge-TKI group, and 8 patients were treated with erlotinib in the Switch-TKI group. There was no significant difference in the proportion of patients receiving osimertinib between the two groups.

\subsection{Treatment sequence after LM development}

The median follow-up period was 10.8 months (95\% confidence interval [CI], 1.9-28.1). The median OS was 6.2 months $(95 \% \mathrm{Cl}, 4.8-9.0)$ in all patients included in our study. The median OS was 6.9 months $(95 \% \mathrm{Cl}, 4.5-9.3)$ in patients treated with Switch-TKI vs. 4.9 months $(95 \% \mathrm{Cl}, 3.0-9.9)$ in patients treated with Rechallenge-TKI. There was no significant difference in the OS (hazard ratio [HR] for death, 1.05; $95 \%$ $\mathrm{Cl}, 0.55-2.00 ; P=0.863)$ between patients treated with Switch-TKI and those treated with Rechallenge-TKI (Fig. 2). The median TTF from the start of EGFR-TKI was 4.5 months $(95 \% \mathrm{Cl}, 3.0-5.2)$ in patients treated with Switch-TKI vs. 3.0 months $(95 \% \mathrm{Cl}, 1.7-8.0)$ in those treated with Rechallenge-TKI (HR, $0.82 ; 95 \% \mathrm{Cl}$, $0.45-1.56 ; P=0.558$ ) (Fig. 3). 


\subsection{Type of EGFR-TKI and other factors}

Nine patients were treated with Switch-Osimertinib, and seven patients were treated with RechallengeOsimertinib. The median OS was 11.3 months $(95 \% \mathrm{Cl}, 4.2-$ Not reached [NR]) in patients treated with Switch-Osimertinib vs. 9.1 months $(95 \% \mathrm{Cl}, 3.0-\mathrm{NR})$ in those treated with Rechallenge-Osimertinib. There was no significant difference in the OS $(\mathrm{HR}, 1.03 ; 95 \% \mathrm{Cl}, 0.32-3.31 ; P=0.948)$ between patients treated with Switch-Osimertinib and those treated with Rechallenge-Osimertinib (Fig. 4A). Likewise, there was no significant difference in the TTF $(\mathrm{HR}, 1.01 ; 95 \% \mathrm{Cl}, 0.32-3.16, P=0.980)$ between patients treated with Switch-Osimertinib and those treated with Rechallenge-Osimertinib (Fig. 4B).

Regarding the patients treated with erlotinib, 26 patients were treated with Switch-Erlotinib, and 8 patients were treated with Rechallenge-Erlotinib. Patients treated with Rechallenge-Erlotinib did not include patients who were EGFR T790M mutation-positive and osimertinib-naïve. The median OS was 5.1 months $(95 \% \mathrm{Cl}, 4.0-7.8)$ in patients treated with Switch-Erlotinib vs. 4.1 months (95\% Cl, $0.4-9.9)$ in those treated with Rechallenge-Erlotinib. There was no significant difference in the OS (HR, 1.30; $95 \% \mathrm{Cl}$, $0.55-2.94, P=0.521)$ and TTF $(\mathrm{HR}, 1.01 ; 95 \% \mathrm{Cl}, 0.43-2.37 ; P=0.973)$ between patients treated with Switch-Erlotinib and those treated with Rechallenge-Erlotinib (Fig. $4 \mathrm{C}$ and D).

In multivariate analysis for OS, patients treated with osimertinib after the onset of $\mathrm{LM}(\mathrm{HR}, 0.25 ; 95 \% \mathrm{Cl}$, $0.11-0.54 ; P<0.001)$ had a significantly better prognosis, and ECOG-PS $0-1(\mathrm{HR}, 0.51 ; 95 \% \mathrm{Cl}, 0.25-$ $1.05 ; P=0.068$ ) tended to be a favorable prognostic factor (Supplementary Table 2).

\section{Discussion}

To our knowledge, this is the first study to evaluate the efficacy of both rechallenge with previously administered EGFR-TKIs and switching to previously unadministered EGFR-TKIs for patients with EGFRmutated NSCLC and LM development after first-line EGFR-TKI treatment failure. Previous studies have shown that switching to previously unadministered EGFR-TKIs or regimen adaptation of EGFR-TKIs provides favorable efficacy for patients with EGFR-mutated NSCLC and LM development after EGFR-TKI treatment failure $[7,9,11]$. Our study demonstrated that patients treated with Rechallenge-TKI had similar survival outcomes to those treated with Switch-TKI. Accordingly, rechallenge with previously administered EGFR-TKIs may be a treatment option for patients with EGFR-mutated NSCLC and LM development after first-line EGFR-TKI failure.

Previous studies have also demonstrated the efficacy of rechallenge with gefitinib and afatinib in patients with EGFR-mutated NSCLC after acquiring resistance to EGFR-TKIs [17-19]. The mechanisms of effect for EGFR-TKI rechallenge may be attributed to the re-sensitization of cancer cells to EGFR-TKIs during the period of time when they are not exposed to EGFR-TKIs [17, 20], and the histological heterogeneity, including sensitive and resistant EGFR-mutant tumor cells, after they have acquired resistance to EGFRTKIs [21, 22]. 
Approximately $80 \%$ of the patients in our study had no extra-CNS disease progression at the onset of LM. Local control of LM may be essential for patients with NSCLC and LM. However, despite the urgent need, there is no effective therapy for local control of $\operatorname{LM}[1,4,14]$. Adding WBRT also showed no improvement in outcomes among patients treated with EGFR-TKIs, consistent with the results of previous studies [14, 23]. Other studies revealed that the CSF/plasma ratio or CSF/blood ratio was $1 \%$ for gefitinib or afatinib, $3-5 \%$ for erlotinib, and $3-32 \%$ for osimertinib $[13,24-27]$. Due to its high penetration into the CSF, erlotinib may provide more favorable local control of LM than gefitinib [7]. Furthermore, recent studies have demonstrated that the efficacy of osimertinib appears to be superior to that of first- and secondgeneration EGFR-TKIs in patients with EGFR-mutated NSCLC and LM [8, 9]. Because of the higher efficacy of erlotinib and osimertinib for LM, both EGFR-TKIs may achieve favorable efficacy for LM when administered not only as Switch-TKI but also as Rechallenge-TKI.

Osimertinib is a standard first-line therapy for patients with metastatic EGFR-mutated NSCLC [15, 28]. For patients treated with osimertinib in our study, there was no significant difference in OS, regardless of previous treatment with osimertinib. Several studies have demonstrated that osimertinib may achieve a more favorable efficacy for LM in patients with EGFR-mutated NSCLC $[1,9,10]$. The results of our study indicate that rechallenge with osimertinib may be a better treatment option for LM development after the failure of osimertinib as a first-line treatment.

Despite the aforementioned findings, there were some limitations to our study. First, our analysis was limited by its retrospective nature and the inability to account for unknown confounders. The small sample size had the potential to affect statistical power. Moreover, this study was conducted in a cohort derived from a single institution and was not validated independently. The survival outcomes of EGFRTKI treatment for LM in our study were poor compared to those in previous studies because patients with ECOG-PS of 2 or higher were more frequent than those in previous studies $[4,9,11]$. In addition, our study included patients with LM development after EGFR-TKI treatment failure, which potentially contributed to the poor survival outcomes. Rechallenge-Erlotinib in our study did not include EGFR T790M mutationpositive and osimertinib-naïve patients. Therefore, patients with EGFR T790M mutation-positive status after treatment with erlotinib may benefit from osimertinib, as suggested by previous studies $[8,9,26]$. We consider that further multicenter studies with large sample sizes or prospective studies are needed to further validate the efficacy of rechallenge with previously administered EGFR-TKIs for patients who develop LM after EGFR-TKI treatment failure, especially that of Rechallenge-Osimertinib, which is the standard first-line treatment for EGFR-mutated NSCLC patients.

In conclusion, our findings suggest that rechallenge with previously administered EGFR-TKI may be an effective treatment option for patients with EGFR-mutated NSCLC and LM development after failure of treatment with EGFR-TKI.

\section{Declarations}


We thank Editage (https://www.editage.jp) for editing this manuscript.

\section{Funding sources}

This research did not receive any specific grants from funding agencies in the public, commercial, or notfor-profit sectors.

\section{Author contributions}

$\mathrm{TM}$ and $\mathrm{KH}$ wrote the manuscript and researched data. $\mathrm{KH}$ reviewed and edited the manuscript. $\mathrm{KM}$ is a professional biostatistician and responsible for statistical analysis. All authors reviewed, approved the final version of the manuscript.

\section{Ethics approval}

The institutional ethics review board of Shizuoka Cancer Center approved this study (approval no. J2020177-2020-1). All procedures performed in studies involving human participants were in accordance with 1964 Helsinki declaration and its later amendments or with comparable ethical standards.

\section{Informed consent}

For this type of study, formal consent is not required. We have also applied an opt-out method to obtain consent for this study by posting a document about this study. The document has been approved by the institutional ethics review board of Shizuoka Cancer Center.

\section{Conflict of interest statement}

Dr. Kenmotsu reports grants and personal fees from Chugai Pharmaceutical Co, Ltd., personal fees from Ono Pharmaceutical Co, Ltd. , personal fees from Boeringer Ingelheim, personal fees from Eli Lilly K.K, personal fees from Kyowa Hakko Kirin Co., Ltd., personal fees from Bristol-Myers Squibb, personal fees from MSD, grants and personal fees from Novartis Pharma K.K., grants and personal fees from DaiichiSankyo Co., Ltd., grants and personal fees from AstraZeneca K.K., personal fees from Pfizer, personal fees from Taiho Pharma, outside the submitted work. Dr. Mamesaya reports personal fees from AstraZeneca KK, Pfizer Japan, Inc., personal fees from Chugai Pharmaceutical Co., Ltd., grants and personal fees from Boehringer Ingelheim, personal fees from MSD K.K., personal fees from TAIHO PHARMACEUTICAL CO., LTD., personal fees from ONO PHARMACEUTICAL CO., LTD., outside the submitted work. Dr. Kobayashi reports personal fees from Eli Lilly K.K, personal fees from Taiho Pharmaceutical, personal fees from AstraZeneca, outside the submitted work. Dr. Omori reports personal fees from Chugai Pharmaceutical Co., Ltd., Ono Pharmaceutical, AstraZeneca K.K., Boehringer Ingelheim, Taiho Pharmaceutical, and MSD, which are unrelated to the submitted work. Dr. Wakuda reports grants and personal fees from Chugai Pharmaceutical Co., Ltd., personal fees from Taiho Pharmaceutical, personal fees from Boehringer Ingelheim, personal fees from Eli Lilly K.K., personal fees from Ono Pharmaceutical, personal fees from MSD, grants and personal fees from Astrazeneca, grants from 
Novartis, grants from Abbvie, outside the submitted work. Dr. Ono reports grants from Taiho Pharmaceutical, grants from Ono Pharmaceutical, grants from Chugai Pharmaceutical Co., Ltd., grants from Novartis Pharma K.K., outside the submitted work. Dr. Murakami reports personal fees from AstraZeneca K.K., Ono Pharmaceutical, Bristol-Myers Squibb Japan, Chugai Pharmaceutical Co., Ltd., Pfizer Inc., Novartis Pharma K.K., Boehringer Ingelheim, Taiho Pharmaceutical, Eli Lilly K.K., and MSD, which are unrelated to the submitted work. Dr. Harada reports personal fees from Daiichi Sankyo Pharmaceutical Co. during the conduct of the study as well as personal fees from Daiichi Sankyo Pharmaceutical Co., AstraZeneca K.K., Brain Labo Co., and Chugai Pharmaceutical Co. and grants from the Japan Agency for Medical Research and Development and the National Cancer Center Research and Development Fund, which are unrelated to the submitted work. Dr. Kazuhisa Takahashi reports grants and personal fees from AstraZeneca K.K., Pfizer Japan, Inc., Eli Lilly K.K., MSD, and Boehringer Ingelheim as well as grants from Takeda Pharmaceutical Company Ltd., Chugai Pharmaceutical Co., Ltd., Taiho Pharmaceutical Co., Ltd., KYORIN Pharmaceutical Co., Ltd., Ono Pharmaceutical Co., Ltd., GlaxoSmithKline Consumer Healthcare Japan K.K., SHIONOGI \& CO., LTD., and Novartis Pharma K.K., which are unrelated to the submitted work. Dr. Toshiaki Takahashi reports grants and personal fees from AstraZeneca KK, Pfizer Japan, Inc., grants and personal fees from Eli Lilly Japan K.K., grants and personal fees from Chugai Pharmaceutical Co., Ltd., grants and personal fees from Ono Pharmaceutical Co., Ltd., grants and personal fees from MSD K.K., grants and personal fees from Boehringer Ingelheim Japan, Inc., grants and personal fees from Pfizer Japan, Inc., personal fees from Roche Diagnostics K.K., outside the submitted work. Others - Declarations of interest: none.

\section{References}

[1] Cheng H, Perez-Soler R (2018) Leptomeningeal metastases in non-small-cell lung cancer. Lancet Oncol. 19 e43-e55. https://doi.org/10.1016/S1470-2045(17)30689-7.

[2] Le Rhun E, Taillibert S, Chamberlain MC (2013) Carcinomatous meningitis: leptomeningeal metastases in solid tumors. Surg Neurol Int. 4 S265-S288. https://doi.org/10.4103/2152-7806.111304.

[3] Alexander M, Lin E, Cheng H (2020) Leptomeningeal metastases in non-small cell lung cancer: optimal systemic management in NSCLC with and without driver mutations. Curr Treat Options Oncol. 21 72. https://doi.org/10.1007/s11864-020-00759-3.

[4] Li YS, Jiang BY, Yang JJ et al (2016) Leptomeningeal metastases in patients with NSCLC with EGFR mutations. J Thorac Oncol. 11 1962-1969. https://doi.org/10.1016/j.jtho.2016.06.029.

[5] Wu YL, Zhao Q, Deng L et al (2019) Leptomeningeal metastasis after effective first-generation EGFR TKI treatment of advanced non-small cell lung cancer. Lung Cancer 127 1-5. https://doi.org/10.1016/j.lungcan.2018.11.022.

[6] Lee SJ, Lee JI, Nam DH et al (2013) Leptomeningeal carcinomatosis in non-small-cell lung cancer patients: impact on survival and correlated prognostic factors. J Thorac Oncol. 8 185-191. 
https://doi.org/10.1097/JT0.0b013e3182773f21.

[7] Lee E, Keam B, Kim DW et al (2013) Erlotinib versus gefitinib for control of leptomeningeal carcinomatosis in non-small-cell lung cancer. J Thorac Oncol. 8 1069-1074. https://doi.org/10.1097/JT0.0b013e318294c8e8.

[8] Ahn MJ, Chiu CH, Cheng Y et al (2020) Osimertinib for patients with leptomeningeal metastases associated with EGFR T790M-positive advanced NSCLC: the AURA leptomeningeal metastases analysis. J Thorac Oncol. 15 637-648. https://doi.org/10.1016/j.jtho.2019.12.113.

[9] Lee J, Choi Y, Han J et al (2020) Osimertinib improves overall survival in patients with EGFRmutated NSCLC with leptomeningeal metastases regardless of T790M mutational status. J Thorac Oncol. 15 1758-1766. https://doi.org/10.1016/j.jtho.2020.06.018.

[10] Yang JCH, Kim SW, Kim DW et al (2020) Osimertinib in patients with epidermal growth factor receptor mutation-positive non-small-cell lung cancer and leptomeningeal metastases: the BLOOM study. J Clin Oncol. 38 538-547. https://doi.org/10.1200/JC0.19.00457.

[11] Flippot R, Biondani P, Auclin E et al (2019) Activity of EGFR tyrosine kinase inhibitors in NSCLC with refractory leptomeningeal metastases. J Thorac Oncol. 14 1400-1407. https://doi.org/10.1016/j.jtho.2019.05.007.

[12] Nosaki K, Yamanaka T, Hamada A et al (2020) Erlotinib for non-small cell lung cancer with leptomeningeal metastases: a phase II study (LOGIK1101). Oncologist 25 e1869-e1878. https://doi.org/10.1634/theoncologist.2020-0640.

[13] Togashi Y, Masago K, Masuda S et al (2012) Cerebrospinal fluid concentration of gefitinib and erlotinib in patients with non-small cell lung cancer. Cancer Chemother Pharmacol. 70 399-405. https://doi.org/10.1007/s00280-012-1929-4.

[14] Yan W, Liu Y, Li J et al (2019) Whole brain radiation therapy does not improve the overall survival of EGFR-mutant NSCLC patients with leptomeningeal metastasis. Radiat Oncol. 14168. https://doi.org/10.1186/s13014-019-1376-z.

[15] Ramalingam SS, Vansteenkiste J, Planchard D et al (2020) Overall survival with osimertinib in untreated, EGFR-mutated advanced NSCLC. N Engl J Med. 382 41-50. https://doi.org/10.1056/NEJMoa1913662.

[16] Mitsuya K, Nakasu Y, Hayashi N et al (2019) Palliative cerebrospinal fluid shunting for leptomeningeal metastasis-related hydrocephalus in patients with lung adenocarcinoma: a single-center retrospective study. PLOS ONE 14 e0210074. https://doi.org/10.1371/journal.pone.0210074.

[17] Tomizawa Y, Fujita Y, Tamura A et al (2010) Effect of gefitinib re-challenge to initial gefitinib responder with non-small cell lung cancer followed by chemotherapy. Lung Cancer 68 269-272. 
https://doi.org/10.1016/j.lungcan.2009.06.025.

[18] Koizumi T, Agatsuma T, Ikegami K et al (2012) Prospective study of gefitinib readministration after chemotherapy in patients with advanced non-small-cell lung cancer who previously responded to gefitinib. Clin Lung Cancer 13 458-463. https://doi.org/10.1016/j.cllc.2012.01.006.

[19] Song T, Yu W, Wu SX (2014) Subsequent treatment choices for patients with acquired resistance to EGFR-TKIs in non-small cell lung cancer: restore after a drug holiday or switch to another EGFR-TKI? Asian Pac J Cancer Prev. 15 205-213. https://doi.org/10.7314/apjcp.2014.15.1.205.

[20] Li D, Ambrogio L, Shimamura T et al (2008) BIBW2992, an irreversible EGFR/HER2 inhibitor highly effective in preclinical lung cancer models. Oncogene 27 4702-4711. https://doi.org/10.1038/onc.2008.109.

[21] Bozzetti C, Tiseo M, Lagrasta C et al (2008) Comparison between epidermal growth factor receptor (EGFR) gene expression in primary non-small cell lung cancer (NSCLC) and in fine-needle aspirates from distant metastatic sites. J Thorac Oncol. 3 18-22. https://doi.org/10.1097/JT0.0b013e31815e8ba2.

[22] Suda K, Murakami I, Yu H et al (2016) Heterogeneity of EGFR aberrations and correlation with histological structures: analyses of therapy-naive isogenic lung cancer lesions with EGFR mutation. $J$ Thorac Oncol. 11 1711-1717. https://doi.org/10.1016/j.jtho.2016.05.017.

[23] Morris PG, Reiner AS, Szenberg OR et al (2012) Leptomeningeal metastasis from non-small cell lung cancer: survival and the impact of whole brain radiotherapy. J Thorac Oncol. 7 382-385. https://doi.org/10.1097/JT0.0b013e3182398e4f.

[24] Hoffknecht P, Tufman A, Wehler T et al (2015) Efficacy of the irreversible ErbB family blocker afatinib in epidermal growth factor receptor (EGFR) tyrosine kinase inhibitor (TKI)-pretreated Non-smallcell lung cancer patients with brain metastases or leptomeningeal disease. J Thorac Oncol. 10 156-163. https://doi.org/10.1097/JT0.0000000000000380.

[25] Togashi Y, Masago K, Fukudo M et al (2010) Cerebrospinal fluid concentration of erlotinib and its active metabolite OSI-420 in patients with central nervous system metastases of non-small cell lung cancer. J Thorac Oncol. 5 950-955. https://doi.org/10.1097/JT0.0b013e3181e2138b.

[26] Nanjo S, Hata A, Okuda C et al (2018) Standard-dose osimertinib for refractory leptomeningeal metastases in T790M-positive EGFR-mutant non-small cell lung cancer. $\mathrm{Br} \mathrm{J}$ Cancer 118 32-37. https://doi.org/10.1038/bjc.2017.394.

[27] Xing L, Pan Y, Shi Y et al (2018) P1.13-25 efficacy and safety of osimertinib in EGFR T790Mpositive advanced NSCLC patients with brain metastases (Apollo study). J Thorac Oncol. 13 S592. https://doi.org/10.1016/j.jtho.2018.08.882. 


\section{Figures}

\section{Patient flow diagram}

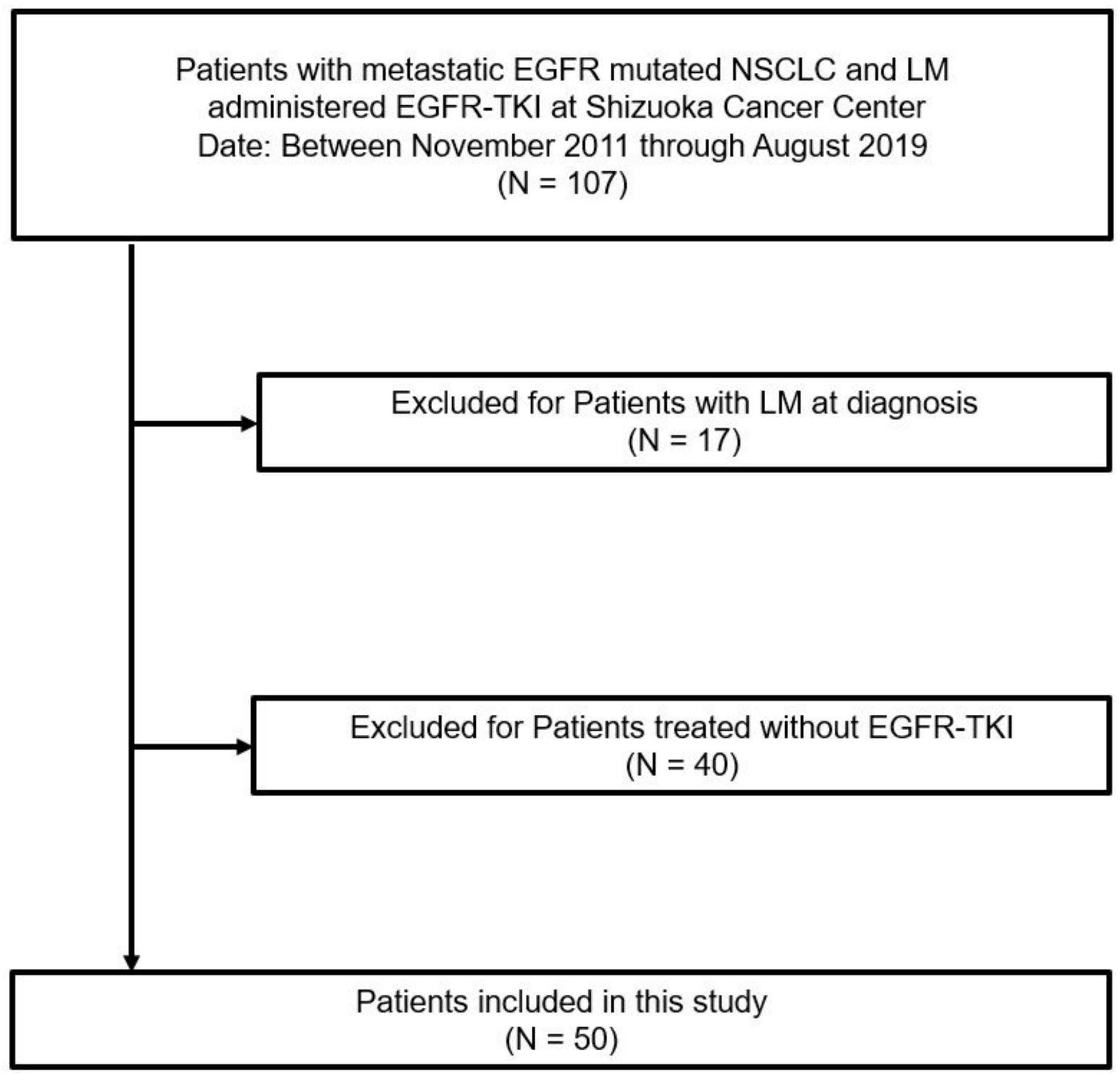

Figure 1 
Study flowchart. EGFR, epidermal growth factor receptor; TKI, tyrosine kinase inhibitor; NSCLC, non-small cell lung cancer; LM, leptomeningeal metastasis.

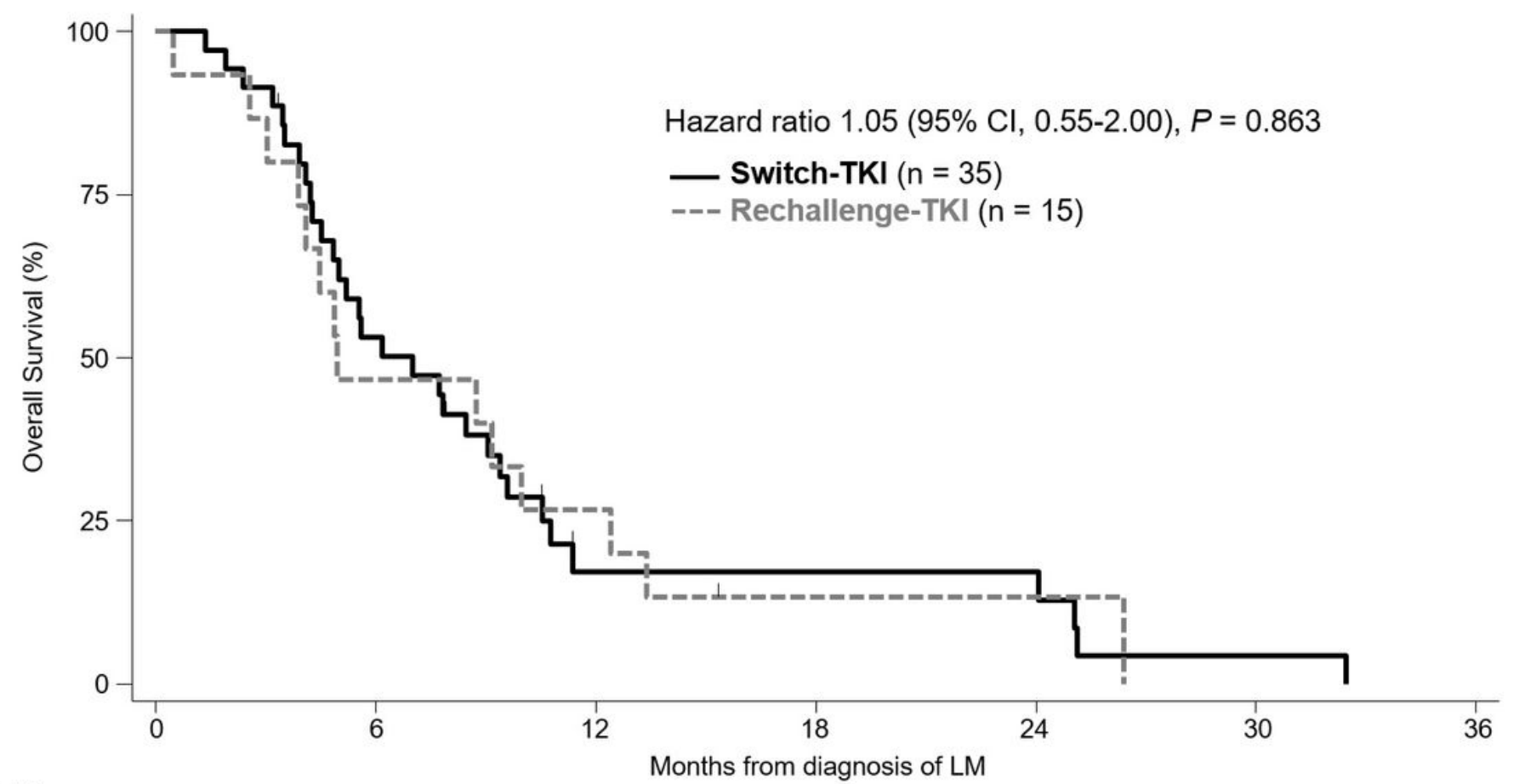

\section{Patients at risk}

Switch-TKI 35

Rechallenge-TKI 15
18

8
4

5
4

2
4

2
0

0

\section{Figure 2}

Kaplan-Meier curves for overall survival according to EGFR-TKI treatment sequences. P-values were calculated using the log-rank test. EGFR, epidermal growth factor receptor; TKI, tyrosine kinase inhibitor. The small vertical lines on the curves indicate patients who are censored. 


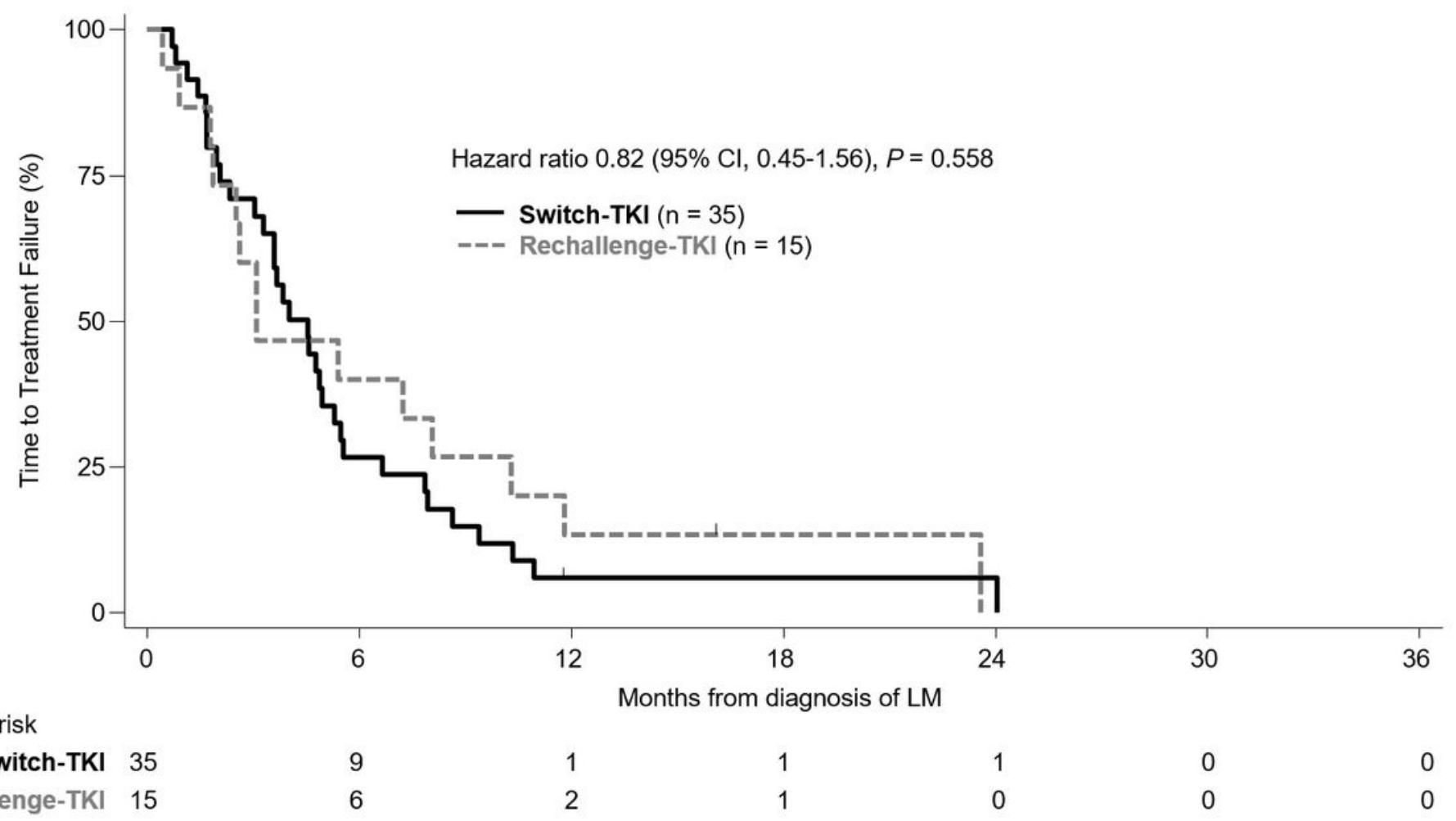

\section{Figure 3}

Kaplan-Meier curves for the time to treatment failure according to EGFR-TKI treatment sequences. Pvalues were calculated using the log-rank test. EGFR, epidermal growth factor receptor; TKI, tyrosine kinase inhibitor. The small vertical lines on the curves indicate patients who are censored. 
A

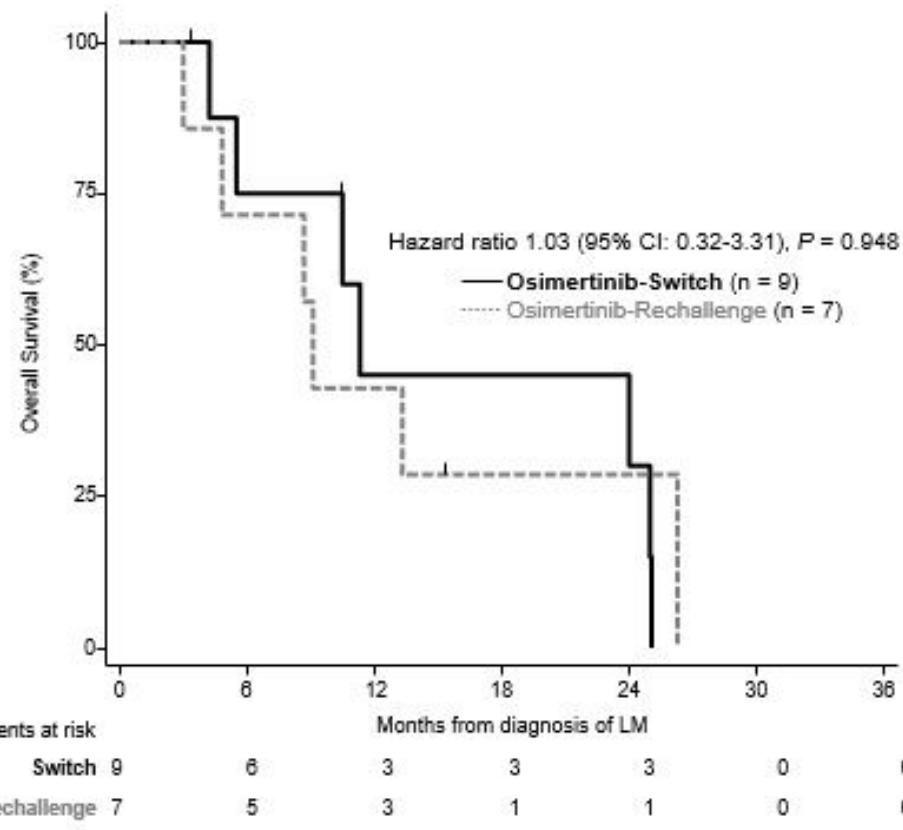

C

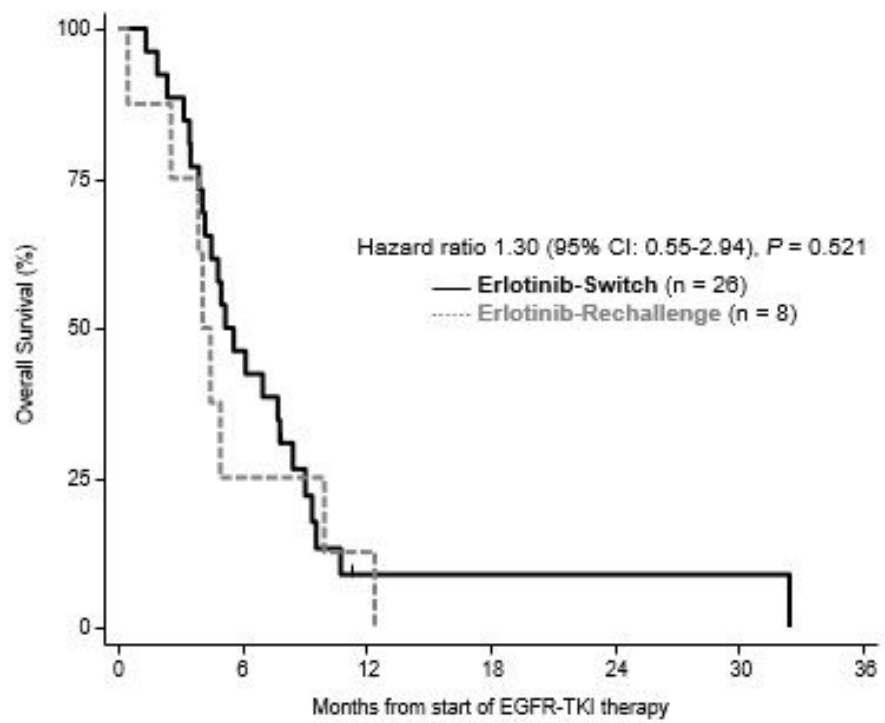

Patients at risk

Switch 28

Rechallenge 8
B

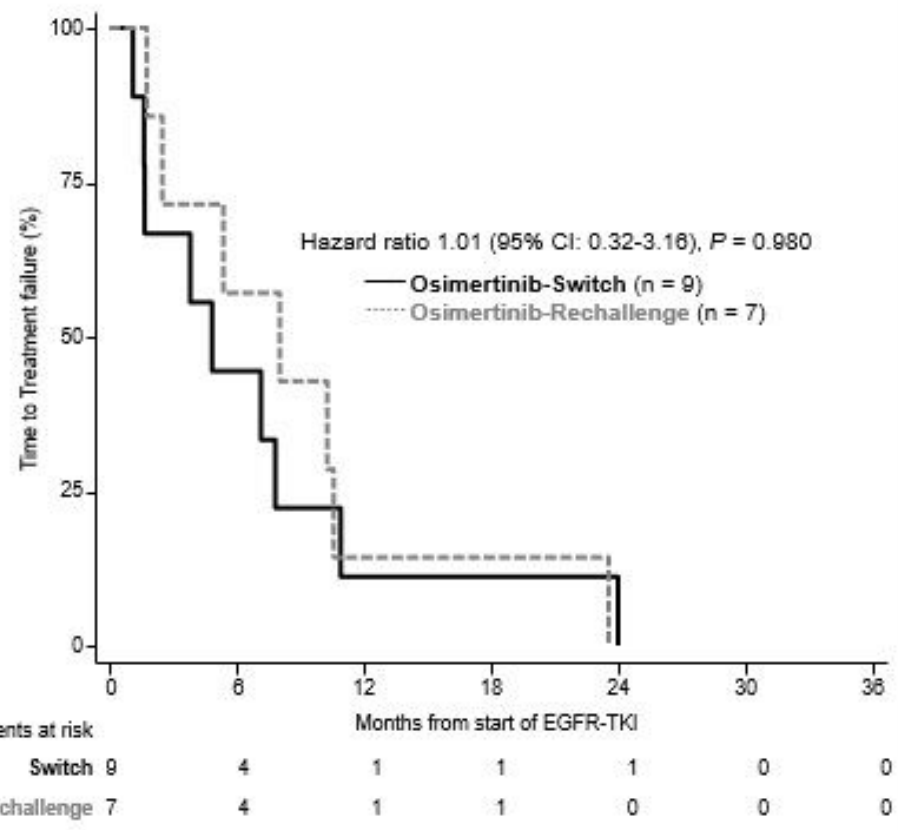

D

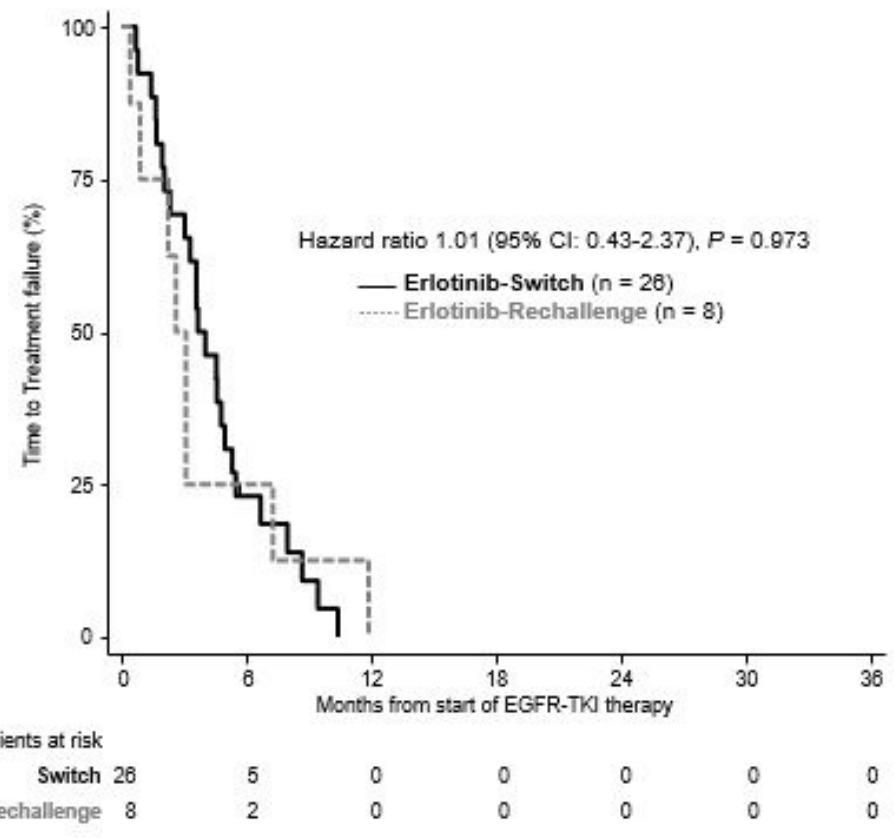

\section{Figure 4}

Kaplan-Meier curves for overall survival (A) and the time to treatment failure (B) according to osimertinib treatment sequences. Kaplan-Meier curves for overall survival (C) and the time to treatment failure (D) according to erlotinib treatment sequences. P-values were calculated using the log-rank test. The small vertical lines on the curves indicate patients who are censored. 